Theor. Appl. Climatol. 45, 3-17 (1992)

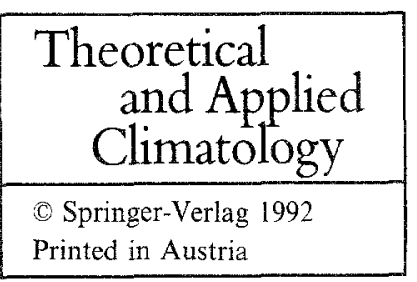

$551.557(494)$

\title{
The Radiosoundings of Payerne: Aspects of the Synoptic-Dynamic Climatology of the Wind Field near Mountain Ranges
}

\author{
M. Furger \\ With 7 Figures \\ Received February 10, 1991
}

\begin{abstract}
Summary
Using routinely collected radiosounding data at Payerne, Switzerland, a climatological examination of the influence of the Alps on the atmosphere is undertaken. The vertical structure of the wind field up to $6200 \mathrm{~m}$ asl is investigated at height intervals of $150 \mathrm{~m}$. The channelling influence of the Alps is found to reach up to about, but not higher than, the $500 \mathrm{hPa}$ level in the mean. Case studies illustrate selected examples of wind profiles and thus demonstrate the complexity and great variety of observed profiles. The problem of coupling/decoupling of different layers is discussed, and a simple classification scheme is proposed to classify wind profiles with respect to coupling or decoupling. It is found that roughly $2 / 3$ of the profiles are decoupled. The scheme is also compared with the weather type classification of the "Alpenwetterstatistik" of Schüepp (1979).
\end{abstract}

\section{Introduction}

The airflow in the vicinity of mountain barriers experiences a variety of effects which may lead to significant deviations of the flow from its unperturbed state. The cause of these effects can be found in the mechanical and/or thermal forcing on the atmosphere by the orography. Mechanical forcing acts to prevent the flow from following a straight path, while thermal forcing leads to the formation of horizontal pressure gradients and changes in the stability of the atmosphere. Unfortunately, a clear separation of the two mechanisms is in most cases not possible, at least in the analysis of real observations. Nevertheless, the di- vision into mechanical and thermal effects constitutes a simple classification scheme for the observed phenomena. Of a predominantly mechanical nature are channelling, deflection, wave generation, turbulence production by wind shear, blocking, and separation of the airflow. Thermal effects form the numerous circulation systems, local inversions, and baroclinicity, the latter often being important for the formation of low level jets. These features can be assigned to various scales. The scales themselves are often directly related to topographic characteristics like mountain height or width, length of a valley, etc.

Observations give an image of the actual state of that part of the atmosphere where the measurement has been made. Many of the above mentioned features can be identified, e.g., in radiosoundings. The decomposition of such a signal into its components is not readily achieved (McKendry et al., 1986), and moreover the interaction of the various scales is still not well understood. The wind profile of a radiosounding normally shows that the flow field near a mountain range may deviate strongly from a mean, undisturbed state due to small-scale, local perturbations. Thus, it is not surprising that the surface wind often seems to be independent from the wind aloft, sometimes even blowing in the opposite direction. Here the questions arise of a) how typical 
(or frequent) are such phenomena, and b) what processes could be responsible for their generation.

This study points out some characteristics of a near-mountain wind field in the lower half of the troposphere. This is done with the radiosoundings of Payerne, Switzerland. In a first part, mean properties of the wind field are worked out with conventional climatological methods. Answers are sought for the questions of 1) how far up can the influence of the Alps be tracked in the data, and 2 ) is there a distinct level with an abrupt change in the properties of the mean wind field. In a second part, the efforts are concentrated on dynamical aspects, mainly on the issue of the coupling or decoupling of various layers, and thus some case studies are presented to illustrate possible mechanisms causing the observed wind profiles. The third part deals with the classification of such profiles with the aim of gaining insight into the climatological relevance of the various types of wind profiles. To this end a simple classification scheme is proposed and compared with a conventional weather type classification.

\section{Concepts and Methods}

Payerne is situated in the Swiss Middleland about halfway between the Jura mountains and the Alps. The geographic location makes it a favourable station for investigating topographic effects on the wind field for scales smaller than the meso- $\alpha$-scale. This study is undertaken from a synoptic-dy-

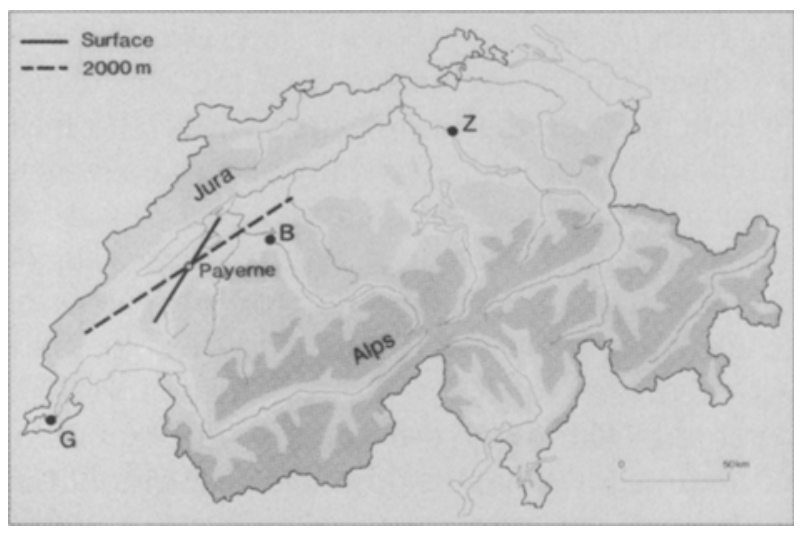

Fig. 1. Topographic situation of Payerne with respect to Jura mountains and Alps. White: $<700 \mathrm{ml}$ asl. Slightly shaded: $700-2000 \mathrm{~m}$ asl. Dark: $>2000 \mathrm{~m}$ asl. The straight lines mark the approximate axes of the Broye valley (solid) and of the Swiss Middleland (dashed). $\mathrm{G}=$ Geneva, $\mathrm{B}=$ Berne, $\mathrm{Z}=\mathrm{Zürich}$ namic-climatological point of view, i.e. the main emphasis is put on long term characteristics for specific meteorological conditions, e.g. weather types. Purely dynamical aspects are not the subject of this paper.

As a pre-existing dataset was examined, the following three sections will first give a description of the geographic location of the measurements and the dataset, and afterwards display the methods applied in the analyses.

\subsection{Geographic Location}

The topographic situation of Payerne with respect to the mesoscale is given in Fig. 1. The surroundings of the station consist of slightly undulating terrain with extensive agricultural use. Station height is $491 \mathrm{~m}$ above sea-level. About $20 \mathrm{~km}$ to the north-west and to the south-east, terrain height reaches up to $1600 \mathrm{~m}$ asl, in the Jura mountains and in the Pre-Alps. Farther to the south-east the Alps reach up to about $4500 \mathrm{~m}$ asl. Hence, in the lower levels the orography around Payerne is characterized by a large SW-NE valley (the Swiss Middleland), whereas in the higher levels the orography shows the characteristics of the edge of a barrier (the Alps). The location of the transition zone between these two regimes will be discussed in a later section. The lowest part of the atmosphere above Payerne is dominated by the Broye valley, which is directed from SSW to NNE.

\subsection{Dataset}

The dataset for this study consists of 3652 radiosoundings routinely collected at 00 and 12 UTC during the period $1981-85$ by the Payerne Aerological Station of the Swiss Meteorological Institute. To improve the vertical resolution, the actual measurements made every $30 \mathrm{~s}$ for pressure, temperature and humidity and every $60 \mathrm{~s}$ for the windvector were used instead of the sounding reports in the international meteorological code for upper air data (TEMP code). These time intervals yield a vertical spacing of about $180 \mathrm{~m}$ in the lower troposphere between individual measurements. The windvector, giving an average of the wind situation within a $360 \mathrm{~m}$ layer, has been attributed to the middle of the respective layer instead of to its upper boundary. Subsequently, these data have been linearly interpolated to $150 \mathrm{~m}$ layers with respect to geopotential height, for reasons of con- 
venience. For this procedure the wind vector has been decomposed into $\mathrm{u}$ and $\mathrm{v}$ components. Only the data below $6200 \mathrm{~m}$ asl have been considered in this study. In the range between 500 and $6200 \mathrm{~m}$ asl 39 levels find their place, being numbered from the surface to $6200 \mathrm{~m}$.

The quality of the Payerne data has been discussed by Steinacker et al. $(1987,1988)$ for the ALPEX-SOP. They found the soundings to be consistent with the analyses of the corresponding meteorological fields. Systematic errors in geopotential height were reported to be $1 \mathrm{gpm}$ for the 850 and $700 \mathrm{hPa}$ levels and $5 \mathrm{gpm}$ for the $500 \mathrm{hpa}$ level. Richner and Phillips (1984) reported the relative accuracy in wind speed to be $0.5 \mathrm{~m} / \mathrm{s}$ below $500 \mathrm{hPa}$. As a consequence no further data corrections were necessary except a visual plausibility check.

\subsection{Methods}

Both to characterize the dataset and to get a standard for future comparison, frequency distributions (wind roses) for all levels and wind matrices (Cehak and Pichler, 1968) for combinations of selected levels were computed.

To investigate statistically the differences between wind directions at different levels, wind matrices can be constructed. These nxn-matrices consist of elements $h_{i j}$ representing the number of cases where wind direction is simultaneously $i$ at one level and $\mathrm{j}$ at the other. The indices $\mathrm{i}$ and $\mathrm{j}$ are running from 1 to $\mathrm{n}$, with $\mathrm{n}$ being the number of direction classes (here: 36 ). Calms were excluded. To simplify the task of visually comparing different matrices, they are represented graphically as contour plots with a contour interval of 5 units; see Fig. 3. As a convention for this study the "ordinate" of a matrix will contain the data of the higher of the two levels.

Additional climatological information can be extracted from the matrices by calculating some characterizing parameters, as proposed by Cehak and Pichler (1968). Their formulae have been adapted to our needs. The simplest matrix parameter is the trace $\mathrm{S}$ :

$\mathrm{S}=\Sigma \mathrm{h}_{\mathrm{ii}}$.

$\mathrm{S}$ gives the share of identical wind directions at the two levels. The sum over the four diagonals adjacing to the main diagonal on both sides,

$$
\begin{aligned}
& S_{D}=\Sigma\left(h_{i-1, i}+h_{i-2, i}+h_{i-3, i}+h_{i-4, i}\right) \\
& +\Sigma\left(h_{i+1, i}+h_{i+2, i}+h_{i+3, i}+h_{i+4, i}\right),
\end{aligned}
$$

is a measure for the occurrence of rotation angles less than $\pm 40^{\circ}$ between the respective levels. Note that for correct computation the cyclic property of the wind direction has to be accounted for. The difference of the two sums in (2) is the rotation parameter

$$
\begin{aligned}
\mathrm{D}=\Sigma\left(\mathrm{h}_{\mathrm{i}-1, \mathrm{i}}+\mathrm{h}_{\mathrm{i}-2, \mathrm{i}}+\mathrm{h}_{\mathrm{i}-3, \mathrm{i}}+\mathrm{h}_{\mathrm{i}-4, \mathrm{i}}\right) & \\
- & -\Sigma\left(\mathrm{h}_{\mathrm{i}+1, \mathrm{i}}+\mathrm{h}_{\mathrm{i}+2, \mathrm{i}}+\mathrm{h}_{\mathrm{i}+3, \mathrm{i}}+\mathrm{h}_{\mathrm{i}+4, \mathrm{i}}\right),
\end{aligned}
$$

and gives the information whether clockwise or counterclockwise rotations between the two levels dominate, negative signs indicating in our case clockwise rotations from the lower to the higher level. The parameter

$\mathrm{R}=\Sigma \mathrm{h}_{\mathrm{ij}}-\mathrm{S}-\mathrm{S}_{\mathrm{D}}$

is a measure of the cases with rotation angles greater than $\pm 40^{\circ}$.

From a dynamical point of view the calculation of profiles of gradient Richardson number (Ri), Brunt-Väisälä frequency $(\mathrm{N})$, vertical velocity of the air (w) etc. is useful for an interpretation of the measurements. Whereas $\mathrm{Ri}$ and $\mathrm{N}$ are calculated in a straightforward manner, the calculation of $w$ is a bit more complicated. As the original soundings contain geopotential height as a function of elapsed time after start, the local ascent rate $\mathrm{W}^{\prime}$ of the balloon can be calculated simply by $\mathrm{W}^{\prime}=\Delta \mathrm{h} / \Delta \mathrm{t}$ for each layer. The mean ascent rate $\mathrm{W}$ is the average of all $\mathrm{W}^{\prime}$. An estimate of the vertical component of the wind vector in layer $\mathrm{k}$ is then

$\mathrm{w}_{\mathrm{k}}=\mathrm{W}_{\mathrm{k}}^{\prime}-\mathrm{W}$

$\mathrm{W}_{\mathrm{k}}$ averages to zero, if summed over all levels. The calculation of $\mathrm{w}$ is very helpful for pointing out the existence of certain types of gravity waves.

Both types of information, the climatological as well as the dynamical, should provide us with the knowledge necessary for the assignment of measured profiles to meteorological processes, and this in turn is fundamental for a classification scheme of profiles which is based on the problem of coupling and decoupling. 


\section{Climatological Aspects}

\subsection{Wind Roses}

Wind roses for Payerne have been published for several standard levels (e.g. Reuter et al., 1966; Binder et al., 1989; Furger et al., 1989). Figure 2 gives a version of a contour plot of the frequencies for all 39 levels. The cut in the cyclic distribution was set at $130^{\circ}$, where there is a natural frequency minimum.

Proceeding from top to bottom, the increasing perturbation of the wind field due to the orography can be recognized. At $6200 \mathrm{~m}$ there is a broad frequency maximum in the westerly quadrants, the maximum lying in the class $260^{\circ}$. The distribution is unimodal, and exhibits the signature of the midlatitude westerlies. At about $3500 \mathrm{~m}$ this distribution starts to split, and below $2500 \mathrm{~m}$ we find a bimodal distribution, the two branches reaching their maximum and slimmest shape at $650 \mathrm{~m}$. The transition zone between the two distributions thus extends roughly $1000 \mathrm{~m}$, the tran-

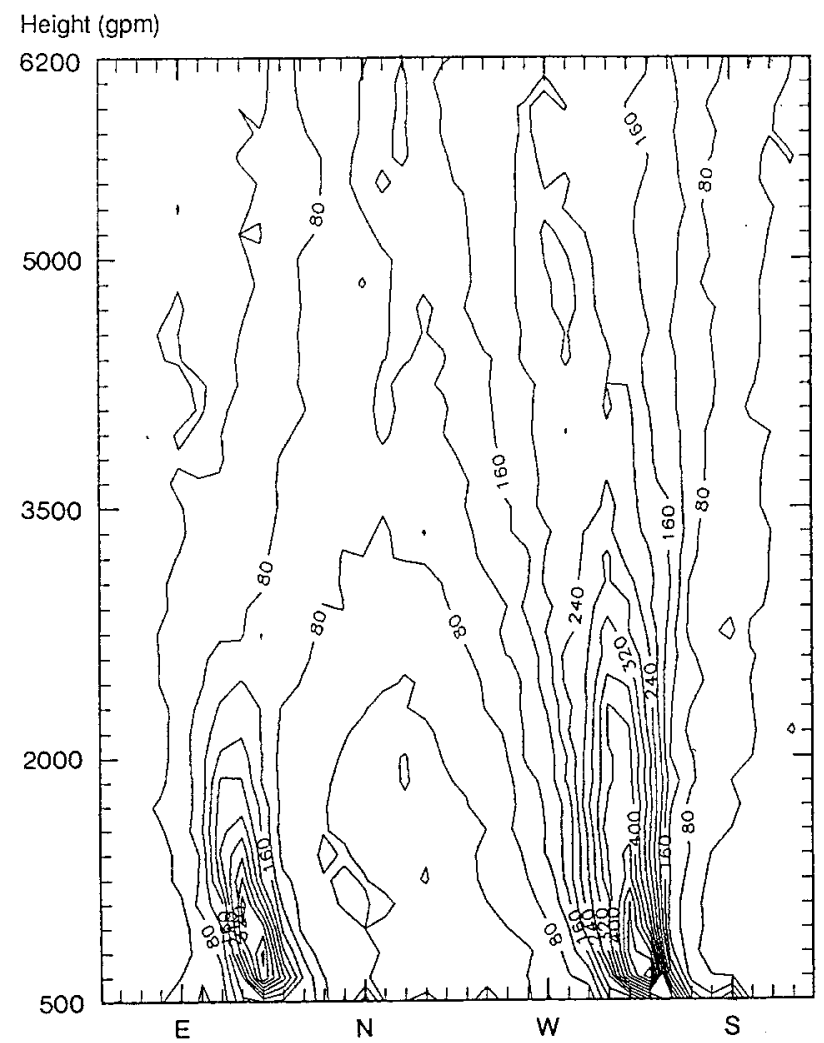

Fig. 2. Frequency distributions of wind direction at 39 levels from surface $(500 \mathrm{~m}$ asl) to $6200 \mathrm{~m}$ asl. Level spacing $150 \mathrm{~m}$. $10 \mathrm{deg}$ classes. Contour intervals 40 units. Calms were excluded sition itself being quite smooth and not showing any abrupt changes or other extravagances. Below this zone the two branches suffer from a significant disequilibrium, the SW branch roughly counting twice as many cases as the NE branch. This can again be explained by the westerlies. The NE branch can often be attributed to the "bise", a regional cold wind typical of this area (Wanner and Furger, 1990). The NE branch falls off much more rapidly with height than the $\mathrm{SW}$ branch. This behaviour is mainly caused by deflection of easterly winds at the Jura mountains, while the SW branch shows the deflecting effects of the Alpine barrier. In this way the influence on westerly winds reaches higher up, but at the same time becomes more diffuse with increasing height and distance to the obstacle.

Clearly visible in Fig. 2 is the rotation of the maximum frequency towards SSW and NNE, respectively, in the lowest few hundred meters. This phenomenon can be attributed to the Broye valley. The main axis of this valley lies exactly parallel to the directions of the frequency maxima (Fig. 1). This hypothesis is further stressed by the diurnal variation of the wind vector (not shown here), which exhibits characteristics of a valley wind system in the lowest few hundred meters (actually, at the $850 \mathrm{hPa}$ level $(\approx 1500 \mathrm{~m})$ and above there is no longer a significant diurnal cycle in the wind directions).

\subsection{Wind Matrices and Characterizing Parameters}

Figure 3 shows a selection of wind matrices for the whole period 1981-85. The corresponding values of characterizing parameters are given in Table 1. Again, we proceed from the "undisturbed" level towards the level with strongest topographic influence, i.e. from top to bottom.

The matrix in Fig. 3 a can be regarded as almost undisturbed, despite the distance of $1.5 \mathrm{~km}$ between the levels. This can be seen from the concentration of datapoints along the diagonal. The bulk of the datapoints lies in the westerly sector between $180^{\circ}$ and $360^{\circ}$, which is also true for all subsequent matrices. The trace $\mathbf{S}$ of this matrix contains $26.7 \%$ of the observations. $92.3 \%$ of the observations have deviations of less than $\pm 40^{\circ}$ ( $R=7.7 \%$ ). As we can see from Table 1 , there is a smooth, but continuous increase (decrease) of 

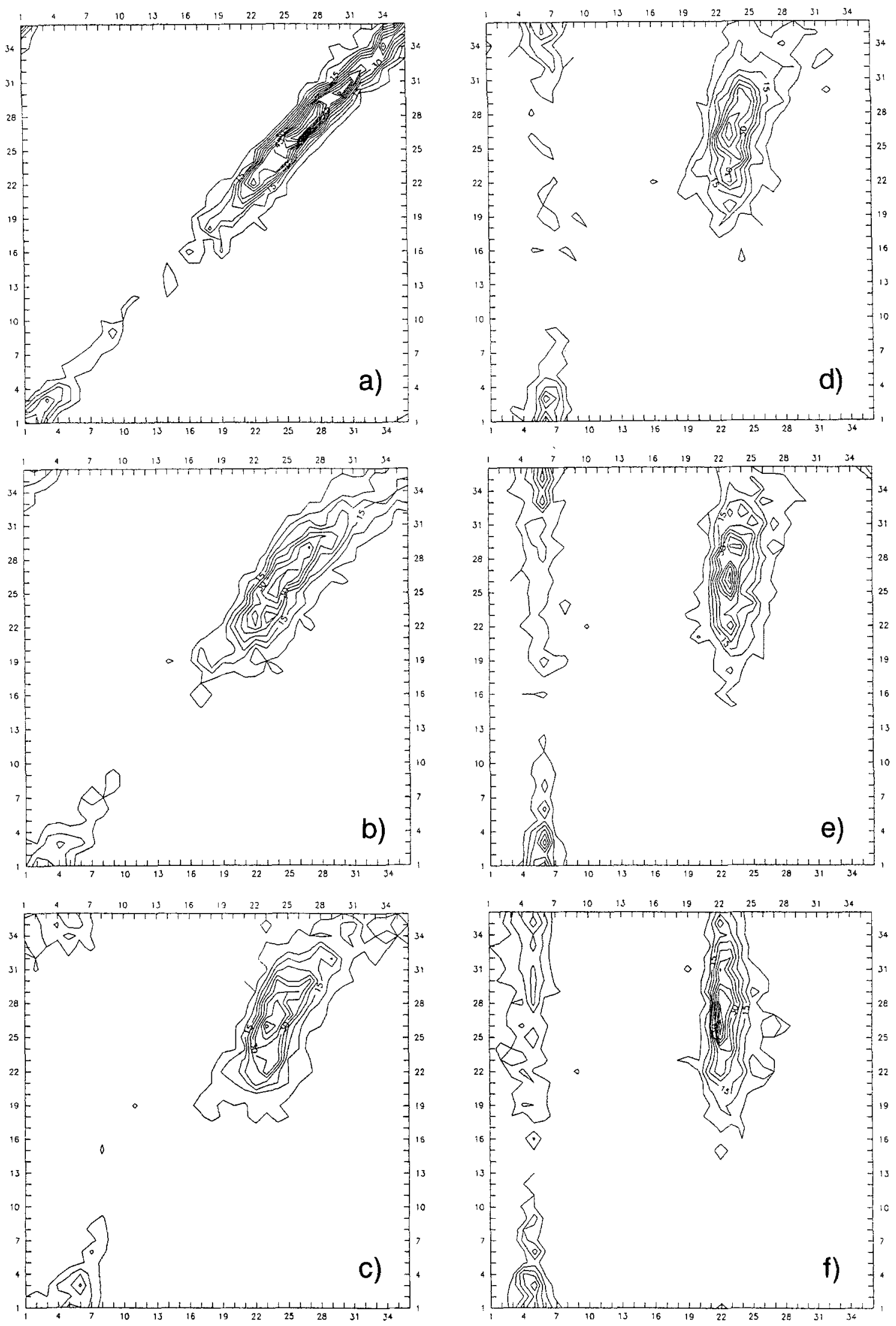

Fig. 3 a-f. Graphical representations of selected wind matrices of the radiosoundings of Payerne 1981-85. Ordinate: level 39 (6200 m asl). Abscissae: a) level $29(4700 \mathrm{~m})$, b) level $19(3200 \mathrm{~m})$, c) level $13(2300 \mathrm{~m})$, d) level $8(1550 \mathrm{~m})$, e) level $5(1100 \mathrm{~m})$, f) level $2(650 \mathrm{~m})$. Contour intervals 5 units. Calms were exluded 
Table 1. Characterizing Parameters in Percent of the Number of Observationsn (Excluding Calms) of the Wind Matrices with Level $39(6200 \mathrm{~m}$ asl $)$ as Ordinate. $d \mathrm{Niv}$ indicates the distance between the levels in $150 \mathrm{~m}$ steps

\begin{tabular}{|c|c|c|c|c|c|c|}
\hline Matrix & dNiv & $\mathrm{n}$ & $S$ & $S_{D}$ & $\mathrm{D}$ & $\mathrm{R}$ \\
\hline 1 & 38 & 3132 & 3.7 & 28.4 & -3.6 & 67.9 \\
\hline 2 & 37 & 3607 & 4.1 & 33.7 & -3.4 & 62.2 \\
\hline 3 & 36 & 3613 & 4.8 & 34.5 & -3.6 & 60.7 \\
\hline 4 & 35 & 3616 & 4.0 & 36.7 & -3.8 & 59.3 \\
\hline 5 & 34 & 3615 & 4.1 & 38.1 & -5.3 & 57.7 \\
\hline 6 & 33 & 3616 & 5.0 & 40.4 & -6.8 & 54.6 \\
\hline 7 & 32 & 3614 & 5.5 & 41.8 & -7.9 & 52.7 \\
\hline 8 & 31 & 3616 & 5.4 & 43.6 & -9.1 & 51.0 \\
\hline 9 & 30 & 3617 & 5.7 & 44.7 & -10.7 & 49.6 \\
\hline 10 & 29 & 3617 & 6.0 & 47.0 & -13.2 & 47.0 \\
\hline 11 & 28 & 3616 & 6.0 & 50.1 & -14.4 & 43.9 \\
\hline 12 & 27 & 3616 & 6.4 & 52.8 & -14.5 & 40.8 \\
\hline 13 & 26 & 3616 & 6.7 & 55.8 & -15.0 & 37.5 \\
\hline 14 & 25 & 3616 & 7.9 & 58.1 & -15.5 & 34.0 \\
\hline 15 & 24 & 3617 & 8.8 & 61.2 & -16.9 & 30.0 \\
\hline 16 & 23 & 3617 & 9.3 & 64.1 & -17.1 & 26.6 \\
\hline 17 & 22 & 3617 & 11.2 & 64.6 & -16.2 & 24.2 \\
\hline 18 & 21 & 3616 & 11.8 & 66.2 & -15.2 & 22.0 \\
\hline 19 & 20 & 3617 & 12.6 & 67.7 & -13.8 & 19.8 \\
\hline 20 & 19 & 3617 & 13.7 & 68.3 & -12.5 & 18.0 \\
\hline 21 & 18 & 3616 & 15.5 & 67.9 & -11.5 & 16.5 \\
\hline 22 & 17 & 3617 & 16.8 & 68.9 & -8.9 & 14.3 \\
\hline 23 & 16 & 3617 & 17.4 & 69.4 & -8.1 & 13.2 \\
\hline 24 & 15 & 3617 & 19.2 & 68.7 & -7.3 & 12.1 \\
\hline 25 & 14 & 3617 & 20.0 & 68.6 & -6.6 & 11.4 \\
\hline 26 & 13 & 3617 & 21.7 & 68.5 & -5.2 & 9.9 \\
\hline 27 & 12 & 3617 & 24.0 & 67.0 & -4.2 & 9.0 \\
\hline 28 & 11 & 3617 & 25.2 & 66.5 & -3.3 & 8.3 \\
\hline 29 & 10 & 3617 & 27.6 & 64.7 & -2.8 & 7.7 \\
\hline 30 & 9 & 3617 & 28.7 & 64.3 & -2.1 & 6.9 \\
\hline 31 & 8 & 3617 & 31.0 & 62.9 & -2.6 & 6.1 \\
\hline 32 & 7 & 3617 & 33.7 & 60.9 & -2.7 & 5.4 \\
\hline 33 & 6 & 3617 & 35.8 & 59.9 & -2.2 & 4.3 \\
\hline 34 & 5 & 3617 & 39.0 & 57.8 & -1.2 & 3.2 \\
\hline 35 & 4 & 3617 & 44.4 & 53.5 & -0.3 & 2.1 \\
\hline 36 & 3 & 3617 & 51.1 & 47.5 & 0.3 & 1.4 \\
\hline 37 & 2 & 3617 & 59.2 & 39.9 & 1.1 & 0.9 \\
\hline 38 & 1 & 3617 & 73.5 & 26.2 & 0.7 & 0.3 \\
\hline
\end{tabular}

$\mathrm{R}(\mathrm{S})$, respectively, with increasing distance between the levels. The rotation parameter $D$ is slightly negative, indicating that clockwise rota- tions occur more frequently. Our opinion is that this rotation is caused by the barrier effect of the Alps where, due to the preponderance of westerly 
winds, the flow is deflected towards the left. Thus the Alps exhibit a direct influence up to about level $36(5900 \mathrm{~m})$, where $\mathrm{D}$ changes its sign. It has not been checked whether the trend towards counterclockwise rotations higher up is increasing, but as there is only a small local maximum at the three levels with $\mathrm{D}>0$, we interpret this to be in favour of our hypothesis.

The next wind matrix (Fig. 3 b) gives qualitatively the same image, except for the spread of the datapoints. Here, in only $12.7 \%$ of the cases does the wind blow from the same direction at both levels, but still $80.2 \%$ of the shear angles are less than $\pm 40^{\circ}$. $D$ has a value of $-13.8 \%$, which is comparatively high. This accounts for a slight, counterclockwise shift of the center of mass of the distributions towards the upper right quadrant in Fig. $3 \mathrm{~b}$. This asymmetry makes plain again the flow-deflecting influence of the Alps. In Fig. 3 c, these ideas are supported further, the parameters $\mathrm{S}, \mathrm{D}$, and $\mathrm{R}$ having values of $6.7 \%,-15.0 \%$, and $37.5 \%$, respectively. New in this matrix is a counterclockwise rotation of the axes of the different data clusters. The angle of this rotation is on the order of $20^{\circ}$. It is interesting to note that the spread of the individual clusters remains roughly constant or even decreases for all subsequent matrices of Fig. 3. This behaviour is expected in the case of channelled flow. Despite these facts the values of $\mathrm{R}$ increase further, due to the definition of $\mathrm{R}$ with respect to the main diagonal of the matrix instead of to the axes of the clusters.

Figure $3 \mathrm{~d}$ shows the matrix for about crest height of the Jura mountains. Now there are first signs of the occurrence of countercurrents, as described by Wippermann (1984) or Gross and Wippermann (1987). The area in the upper left corner of the matrix shows that there is a large number of cases where the wind at the higher level is blowing from the west sector $\left(180^{\circ}\right.$ to $\left.360^{\circ}\right)$, while the wind at the lower level blows from $\mathrm{NE}\left(40^{\circ}\right.$ to $80^{\circ}$ ). This feature is only weakly outlined in Fig. $3 \mathrm{~d}$, but becomes very prominent in Fig. $3 \mathrm{e}$ and $3 \mathrm{f}$. Note, that there are (almost) exclusively countercurrents of one type. Such situations are predominantly linked with westerly flow aloft and easterly flow below. S decreases from $6.7 \%$ to $4.1 \%$ for Figs. $3 \mathrm{~d}$ and $3 \mathrm{f}$, respectively, thus illustrating the negligible amount of cases with parallel flow at the uppermost and lowest levels. One has to be careful with this statement, since parallel flow at these two levels does not necessarily mean that the flow in between is parallel, too.

The re-increase of D below level $16(2750 \mathrm{~m}$ asl) in Table 1 is surprising, because a quick look at the matrices shows a strong asymmetry between the area above and below the main diagonal. Note that in the graphics of Fig. 3 the main diagonal goes from the bottom left corner to the top right corner. Inspection of the indices in Eq. 3 together with the graphics reminds us, however, of the narrow band along the diagonal where frequencies are taken into account. So this feature is primarily a mathematical effect with no further physical relevance.

Flow reversals in the lower layers can occur when the wind aloft rotates across the "critical" direction of about $330^{\circ}$. In this case the winds in the lower layers jump from SW to NE for a rotation of the same sense in the upper level. The opposite point cannot be fixed in the same way due to the natural minimum of cases in the SE sector, where at the same time Payerne is lying in the lee of the mountain range. Note, however, that

Table 2. Characterizing Parameters in Percent of the Number of Observations $n$ (Excluding calms) of the Wind Matrices with Two Neighbouring Levels. dNiv indicates the distance between the levels in $150 \mathrm{~m}$ steps

\begin{tabular}{llrrrrr}
\hline Matrix & dNiv & $\mathrm{n}$ & $\mathrm{S}$ & $\mathrm{S}_{\mathrm{D}}$ & $\mathrm{D}$ & $\mathrm{R}$ \\
\hline $3 \times 2$ & 1 & 3622 & 41.2 & 49.0 & -17.1 & 9.9 \\
$5 \times 4$ & 1 & 3630 & 44.2 & 50.5 & -17.6 & 5.3 \\
$9 \times 8$ & 1 & 3632 & 49.2 & 47.2 & -7.9 & 3.6 \\
$19 \times 18$ & 1 & 3630 & 59.5 & 39.4 & -7.4 & 1.1 \\
$29 \times 28$ & 1 & 3627 & 69.0 & 30.6 & 0.0 & 0.5 \\
$39 \times 38$ & 1 & 3617 & 73.5 & 26.2 & 0.7 & 0.3 \\
\hline
\end{tabular}


the jump in wind direction does not occur in every case.

Table 2 contains the same parameters as Table 1, but for pairs of levels immediately adjacent to each other. The values demonstrate that the similarity of the wind directions increases with increasing distance from the surface. For the uppermost levels, $73.5 \%$ of the cases show identical wind directions, whereas this fraction for levels 2 and 3 is only $41.2 \%$. The frequencies of cases with rotation angles less than $\pm 40^{\circ}$ drop from $99.7 \%$ for matrix $39 \times 38$ to $90.1 \%$ for matrix $3 \times 2$.

\section{Aspects of the Coupling Between Atmospheric Layers}

The issue of inter-level flow relationship is intricate. On one hand the flow behaviour at some location is dictated by the influence of the larger scale meteorological fields (far field interaction), and on the other hand some properties of the flow are exchanged between air parcels by local processes (near-neighbour interaction). This exchange depends strongly on the vertical stability of the atmosphere. Besides these flow-related properties, the underlying orography plays an important rôle, too. The steepness of the side-walls of a valley, for example, may lead to a valley atmosphere more or less independent from the free atmosphere, or to blocking of airmasses. Further complications arise in the atmospheric boundary layer $(\mathrm{ABL})$, which is not only not well defined in mountainous regions, but also not accurately resolved by routine soundings. Consequently, a discussion of the processes in the ABL has to be excluded here.

By examining single profiles it is possible to some degree to recognize locations of decoupling, as will be illustrated in Section 4.2, and to identify some of the underlying processes. However, first we will try to define the terminology of coupling and decoupling.

\subsection{A Qualitative Definition of Coupling}

In general, "coupling" means the mutual influence of several physical systems. For our dataset, we can restrict this conceptual definition to the interaction between various atmospheric layers. In the case of coupling we can postulate the existence of some mechanism(s) for the exchange of the relevant properties, like momentum and kinetic energy, within and between the considered layers. In this sense coupling is connected to the free interlayer exchange of these properties. Two layers are coupled when they show no marked differences in their behaviour, e.g., no strong change in wind direction and/or no jump in wind speed at the interface. Decoupling takes place where these exchange mechanisms are restricted. This may happen in statically stable layers, at marked density
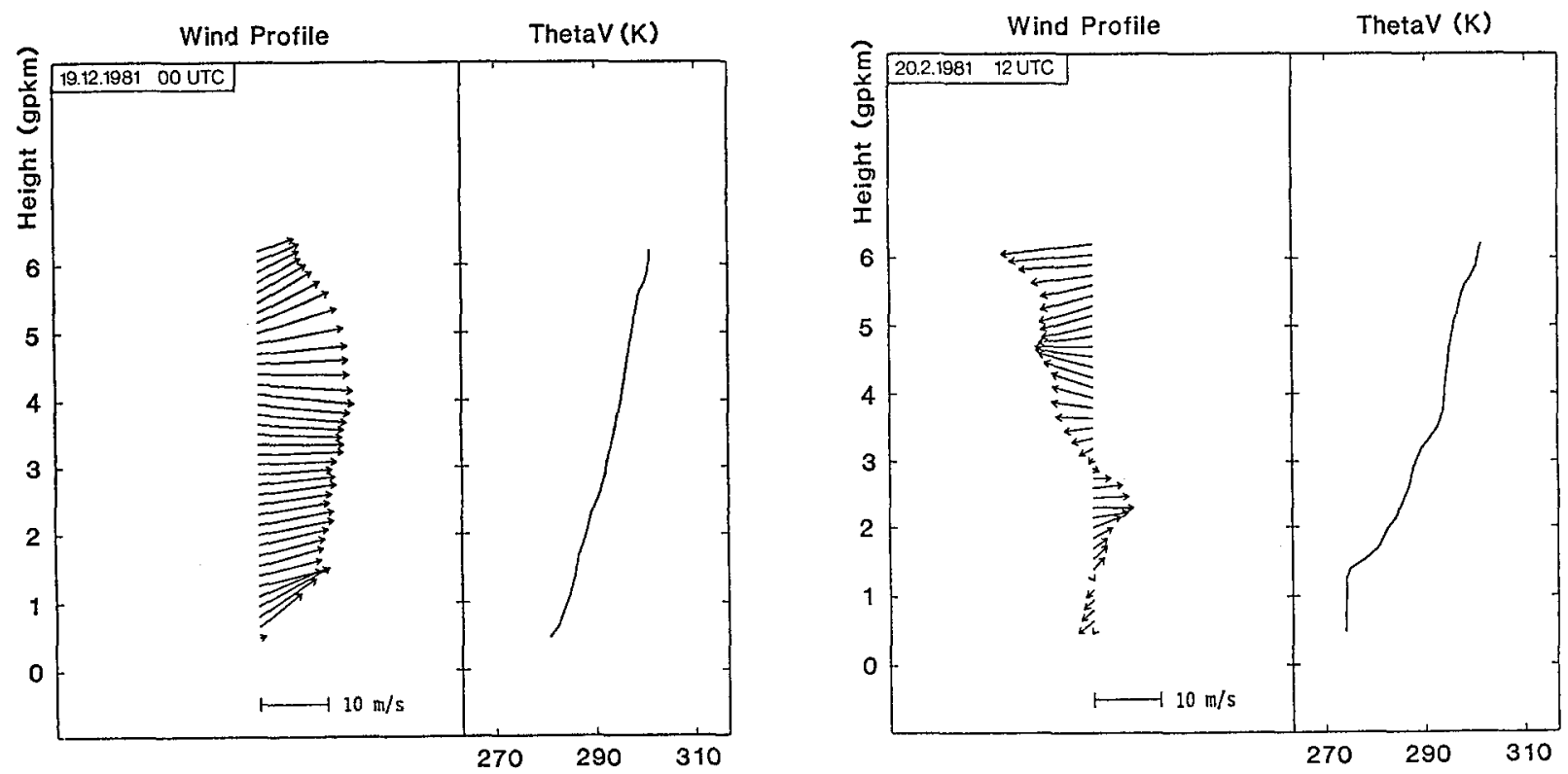

Fig. 4. Two illustrative examples of coupled flow regimes. Left: Profiles for wind and virtual potential temperature for 19 Dec 1981, 00 UTC, showing strong coupling. Right: The same for 20 Feb 1981, 12 UTC, and decoupling 
jumps (elevated inversions) and at critical levels. While inversions often mark air mass boundaries, critical levels occur in conjunction with wind minima and thus directly point to a level of flow decoupling.

Figure 4 gives an illustration of these ideas. While the December case shows a quasi-homogeneous wind field throughout the lower troposphere and therefore good coupling, the February case exhibits an intrusion of dryer air in the layer between 1000 and $2500 \mathrm{~m}$ asl with a strong decoupling of the various wind regimes. The interfaces of the layers are accompanied by strong inversions in the temperature profile.

What physical mechanisms are responsible for the coupling? Basically there are four mechansims exchanging properties like momentum and energy: viscous friction, turbulence at various scales, sec-

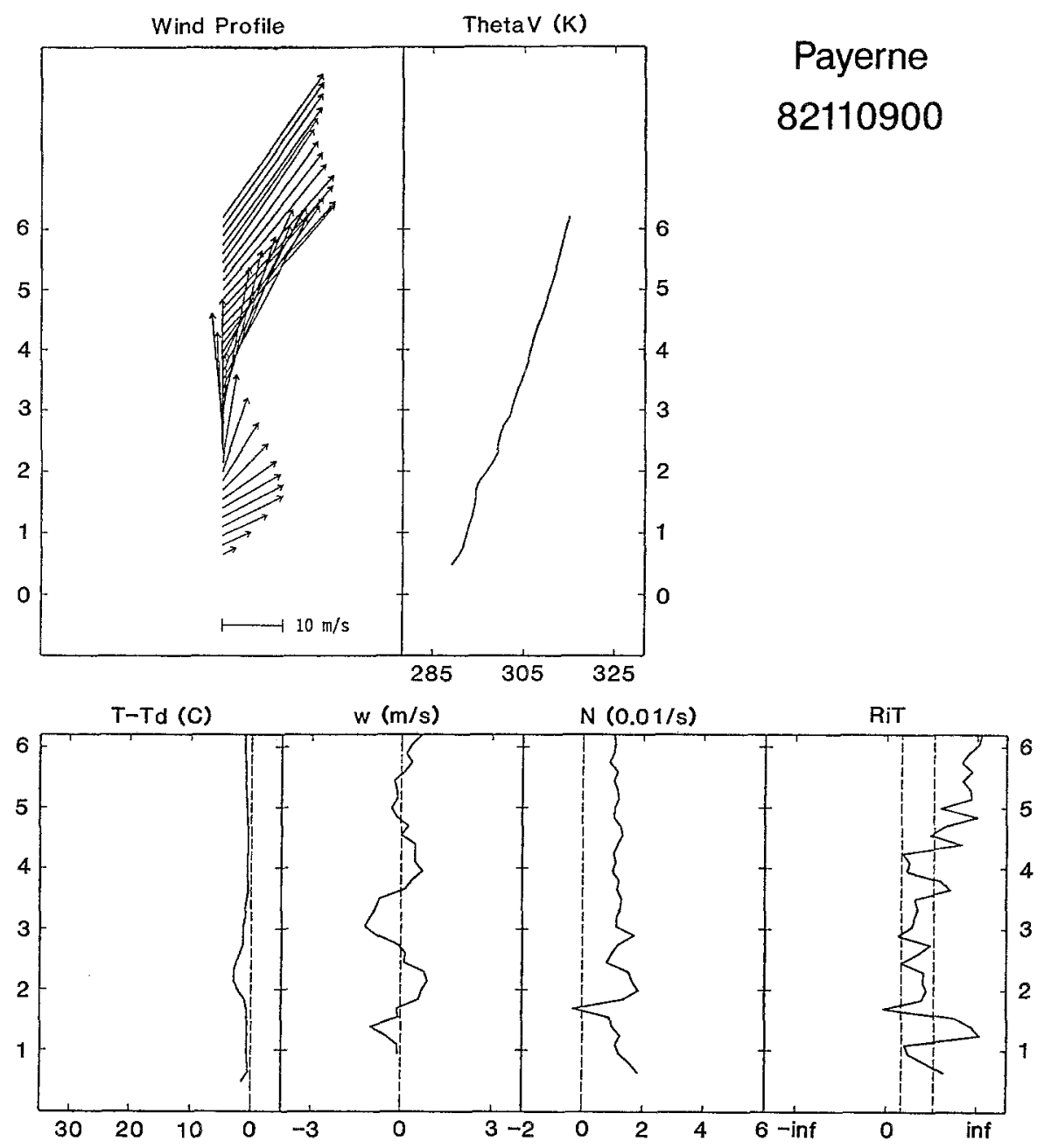

Fig. 5. Profiles for wind, virtual potential temperature (ThetaV), dewpoint depression (T-Td), vertical velocity (w), BruntVäisälä frequency (N) and Richardson number (RiT), for 9 November 1982, 00 UTC. The scale of the latter has been transformed by an arctan-function for graphical convenience, the dashed lines indicating the valuzes of 0.25 and 1

ondary circulations, and waves. Only turbulence and waves can be identified in routine soundings if conditions are favourable, so we restrict ourselves to a discussion of the latter two.

a) Turbulence. Concerning the wind field, turbulence due to (vertical) wind shear is of particular interest. This type of turbulence is typical in the planetary boundary layer (PBL) and at interfaces between different layers. With routine soundings turbulence cannot be measured at all, but the computation of Richardson number profiles helps to determine whether turbulence might have occurred or not.

b) Waves. The wavelengths of gravity waves vary in a range from a few tens of meters to hundreds of kilometers, but in our dataset only wavelengths of less than the order of $10 \mathrm{~km}$ are traceable. Two types of waves are of outstanding im-

\section{Payerne \\ 82110900}


portance in a location like Payerne: lee waves (due to orographic forcing) and Kelvin-Helmholtz waves (due to strong vertical wind shear).

Practically, we have to examine a profile by looking for significant jumps in wind direction and/or speed and for the presence or absence of inversions. Profiles of the vertical velocity $w$, the Richardson number Ri and the Brunt-Väisälä frequency $\mathrm{N}$ have to be consulted to identify waves or turbulence.

\subsection{Some Examples}

To illustrate the validity of the above assumptions we will discuss two examples. The first will be a (lee) wave event, the second a situation with clear air turbulence (CAT).

The foehn case of 8 November 1982 has become a prominent example of a severe, high-reaching foehn (e.g. Seibert 1985, Hoinka 1985). Wave ac- tivity has been reported by glider pilots and was also clearly visible on satellite imagery. The horizontal wavelength was of the order of $\approx 10 \mathrm{~km}$. The sonde needed some 10 minutes to pass one apparent wavelength (a value in good agreement with the Brunt-Väisälä frequency) and was horizontally displaced by about $16 \mathrm{~km}$ during this time. Figure 5 shows the wind and temperature profiles for Payerne for 9 November 1982, 00 UTC. Although the wind profile does not differ much from the noon sounding of the 8th (the strongest foehn phase), the dewpoint depression profile indicates saturation and thus the preceding end of the foehn phase. While the Ri-profile indicates turbulent flow, the w-profile exhibits interesting wave-like structures. Hence, assuming sufficient amplitudes, waves can be detected by routine soundings (cf. Shutts et al. 1988). Unfortunately, small amplitude waves generally are be-

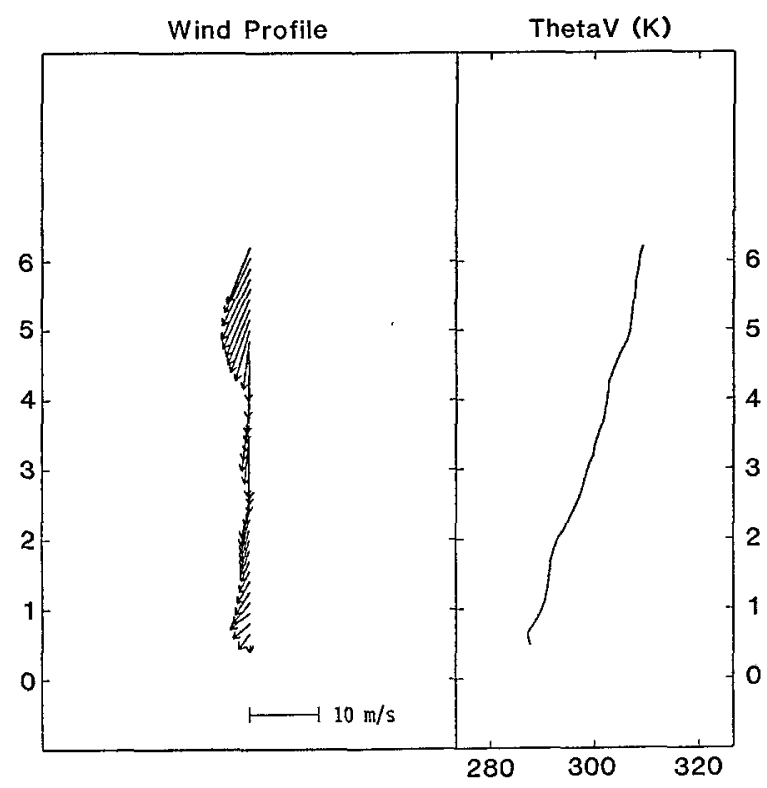

\section{Payerne}

83031112

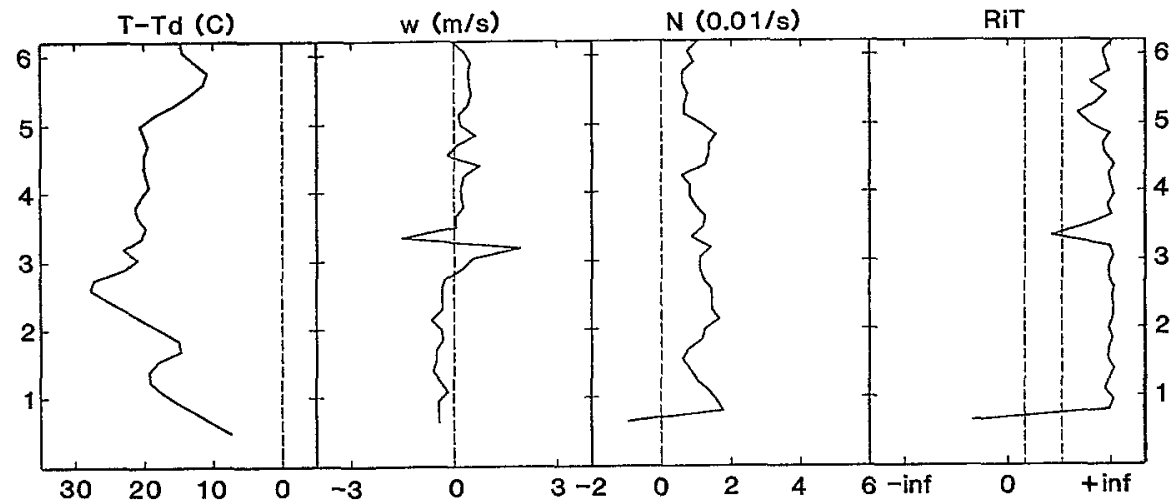

Fig. 6. As Fig. 5, but for 11 March 1983, 12 UTC 
and 2 otherwise. For types 4 and 8 , however, $Q$ has a different meaning. For type $4, Q=2$ marks profiles with a very significant rotation of more than $180^{\circ}$ in a narrow zone. For type 8 this signifies that besides the stagnating air mass there exists a marked rotation of the wind vector. More details and examples of realistic profiles can be found in Furger (1990).

The frequency distribution of these profile types is given in Table 3 . The shear type 6 is the most frequent with $35 \%$, followed by type 8 with $27 \%$ and type 4 with $10 \%$. With respect to coupling/ decoupling, decoupled profiles (types 6,7 and 8) dominate with $66 \%$ of the cases. Coupled (types 1, 2 and 3) and partly coupled profiles (types 4 and 5) show a share of 17 and $15 \%$, respectively. Only $2 \%$ of the profiles are not classifiable. The prominent amount of decoupled types is thought to represent mechanical and thermal effects of the Alps and the Jura mountains, and also some characteristics of midlatitude circulations (fronts).

Table 3. Frequencies of Wind Profile Types. $\mathrm{Q}=1$ certain, $\mathrm{Q}=2$ uncertain classification

\begin{tabular}{lrrrrrrrrrr}
\hline Frequency/Profile type & 1 & 2 & 3 & 4 & 5 & 6 & 7 & 8 & 9 & Total \\
\hline All & 170 & 147 & 301 & 352 & 212 & 1285 & 147 & 990 & 48 & 3652 \\
$\mathrm{Q}=1$ & 134 & 106 & 258 & 331 & 167 & 1065 & 110 & 710 & 22 & 2903 \\
$\mathrm{Q}=2$ & 36 & 41 & 43 & 21 & 45 & 220 & 37 & 280 & 26 & 749 \\
\hline
\end{tabular}

Table 4. Frequencies of Weather Types After Schüepp (1979) Versus Profile Types. The values of the theoretically expected distribution are written in italics. The deviations between the totals of observed and expected distribution are due to rounding errors

\begin{tabular}{|c|c|c|c|c|c|c|c|c|c|c|}
\hline $\begin{array}{l}\text { Weath } \\
\text { type }\end{array}$ & $e_{1}$ & 2 & 3 & 4 & 5 & 6 & 7 & 8 & 9 & Total \\
\hline \multirow[t]{2}{*}{ High } & 7 & 12 & 24 & 70 & 20 & 69 & 9 & 151 & 5 & 367 \\
\hline & 15 & 16 & 32 & 37 & 19 & 124 & 12 & 106 & 5 & 360 \\
\hline \multirow[t]{2}{*}{ Flat } & 14 & 32 & 27 & 76 & 22 & 152 & 16 & 172 & 6 & 517 \\
\hline & 21 & 22 & 45 & 52 & 27 & 175 & 16 & 150 & 7 & 515 \\
\hline \multirow[t]{2}{*}{ Low } & 10 & 4 & 20 & 18 & 5 & 51 & 11 & 24 & 1 & 144 \\
\hline & 6 & 6 & 13 & 15 & 8 & 49 & 5 & 42 & 2 & 146 \\
\hline \multirow[t]{2}{*}{ West } & 14 & 8 & 35 & 1 & 9 & 80 & 8 & 21 & 6 & 182 \\
\hline & 7 & 8 & 16 & $18^{-}$ & 10 & 62 & 6 & 53 & 2 & 182 \\
\hline \multirow[t]{2}{*}{ North } & 2 & 6 & 34 & 4 & 7 & 134 & 3 & 63 & 3 & 256 \\
\hline & 11 & 11 & 22 & 26 & 14 & 87 & 8 & 74 & 4 & 257 \\
\hline \multirow[t]{2}{*}{ East } & 4 & 8 & 4 & 1 & 16 & 30 & 5 & 12 & 1 & 81 \\
\hline & 3 & 4 & 7 & 8 & 4 & 27 & 3 & 23 & 1 & 80 \\
\hline \multirow[t]{2}{*}{ South } & 21 & 5 & 4 & 2 & 14 & 59 & 6 & 65 & 3 & 179 \\
\hline & 7 & 8 & 16 & 18 & 10 & 61 & 6 & 52 & 2 & 180 \\
\hline \multirow[t]{2}{*}{ Misc } & 3 & 4 & 12 & 12 & 4 & 44 & 0 & 21 & 0 & 100 \\
\hline & 4 & 4 & 9 & 10 & 5 & 34 & 3 & 29 & 1 & 99 \\
\hline \multirow[t]{2}{*}{ Total } & 75 & 79 & 160 & 184 & 97 & 619 & 58 & 529 & 25 & 1826 \\
\hline & 74 & 79 & 160 & 184 & 97 & 619 & 59 & 529 & 24 & 1825 \\
\hline
\end{tabular}


yond the possibilities of this type of measurement, despite their physical importance.

In a few cases the w-profile shows a pair of marked peaks at some level, as illustrated in Fig. 6. This indicates that the sonde has been passing through a relatively narrow region with strong vertical motion, both upward and downward. Normally, the w-peaks are associated with a stable layer and significant wind shear. We believe this to be the signature of CAT, since the Ri-profile indicates turbulence, while wind and temperature profiles fulfill the conditions for the occurrence of Kelvin-Helmholtz waves.

\section{Suggestions on a Classification of Wind Profiles}

The classification of wind profiles plays only a minor rôle in comparison with other classification schemes, e.g. classification of weather types, and literature concerning this topic is very scarce (e.g. Essenwanger 1974). Therefore we will propose our own simple classification scheme for wind profiles (section 5.1). It should discriminate the profiles according to their coupling/decoupling characteristics and, at the same time, be as easy to use and as objective as possible. In section 5.2 a comparison with the weather types of the "Alpenwetterstatistik" (Alpine weather statistics) of Schüepp (1979) is made.

\subsection{A Simple Classification Scheme}

A simple approach to a classification scheme can be done by visual examination of the wind profiles. This method is very efficient and gives results that are reproducible to a satisfactory degree.

The classification procedure has primarily to consider the occurrence of wind shear and/or thermal inversions. The wind shear should show a prominent peak if plotted as a shear profile, such that distinct wind regimes become clearly visible. This single criterion has to be satisfied in order to attribute a profile to a decoupled profile type. An inversion at the same height as the shear peak could additionally confirm such an attribution. On the other hand if a profile shows rather smooth variations, it has to be considered a coupled profile type. Types 1, 2 and 3 are fully coupled, 4 and 5 are partially coupled, 6,7 and 8 are decoupled. Type 9 can not be classified in this respect.

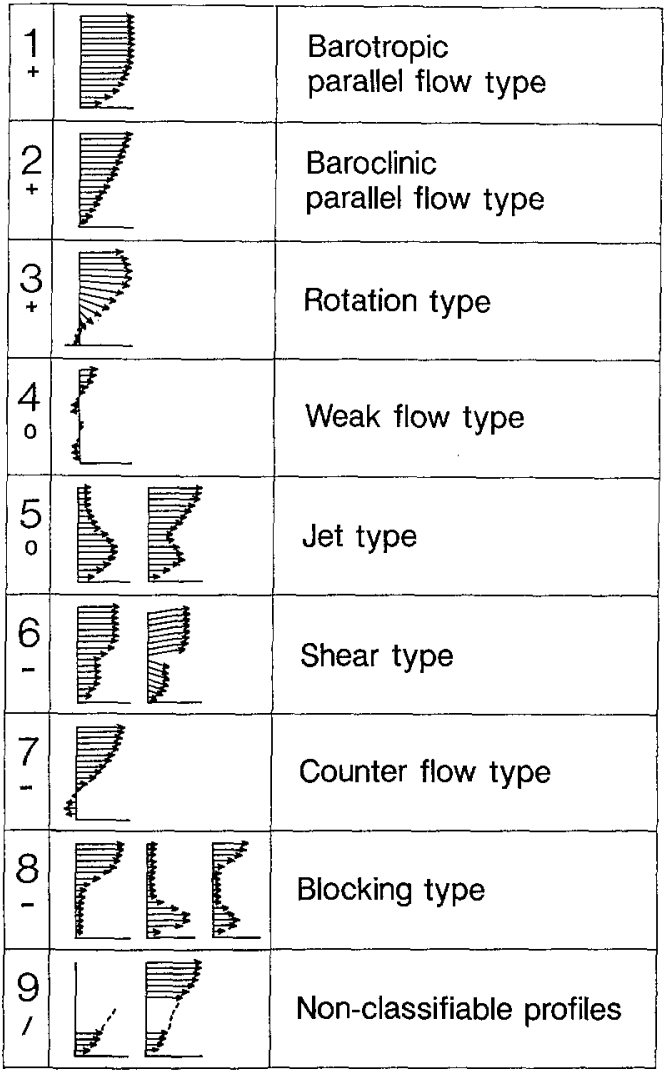

Fig. 7. Schematic of 9 types of wind profiles. The symbols below the type numbers denote coupling $(+)$, decoupling $(-)$, partial coupling (o), and not attributable $(/)$

Figure 7 shows our classification scheme with nine profile types. For types 1 and 2 the hodograph has to lie within a range of $45^{\circ}$, while for type 3 the range must be greater than $45^{\circ}$. Type 4 comprises the cases with maximum speeds less than $7.5 \mathrm{~m} / \mathrm{s}$. Type 5 must show a marked jet-like maximum in wind speed, but without stagnating air (see type 8). Type 6 is characterized by a marked wind shear, either in speed or/and in direction. In type 7 the maximum rotation angle has to exceed $135^{\circ}$. Type 8 contains at least one zone of stagnating air (velocity less than $5 \mathrm{~m} / \mathrm{s}$ for at least four levels). Profiles with larger gaps or missing data are classified as type 9.

There are many profiles that show characterisics of more than one type, of course. In these cases, the profiles were classified according to the most dominant type. In addition, a quality factor $Q$ was attributed to each profile in order to distinguish the degree of certainty of the classification. Q equals 1 for clearly classifiable profiles, 
The location of Payerne shows a clear signature in the sense that (even large) valleys favour the formation of inversions or the sheltering of the wind.

\subsection{On the Dependence of Wind Profile Types on Weather Types}

Finally, it is interesting to know more about the relationship between the profile types and a conventional classification of weather types in order to get some information on the far-field influence. To this end the classification of Schüepp (1979) is used. This classification scheme is based on the 12 UTC synoptic surface and $500 \mathrm{hPa}$ charts, from where the geostrophic wind direction and speed, the geopotential height anomaly, and the angle between isobars and isohypses are extracted. These parameters can be grouped into 40 weather situations (one for each day), which here have been combined to 8 main weather types. Consequently, only noon soundings have been considered for the following discussion.

The profile types vs. weather types are presented in Table 4. For a better comparison it is helpful to calculate a theoretically expected distribution according to

$\mathrm{th}_{\mathrm{ij}}=\left(\mathrm{h}_{\mathrm{i}} \cdot \mathrm{h}_{\cdot \mathrm{j}}\right) / \mathrm{n}$,

where $h_{i}$. and $h_{. j}$ are the column and row totals, and $n$ the total number of observations. This can be done under the assumption of statistical independence of the marginal distributions (Bahrenberg et al., 1985). The estimated frequencies are included in Table 4 in italics. It can be seen that type 1 exhibits its maximum with southerly situations and generally is overrepresented in advective situations, which had to be expected. Type 2 is more or less equally distributed except for flat pressure situations where it occurs more than normal, and we suggest that this type is not strongly dependent on weather types. Type 3 occurs predominantly with westerly and northerly weather types and thus shows the importance of mechanical deflection of the airflow at the Alps. Type 4 is associated with convective, weak-gradient situations, like type 5. However, type 5 also shows an overrepresentation in easterly situations and thus reminds us of the typical structure of bise profiles with its marked jet. In contrast to type 3, type 6 seems to be related to fronts, due to the abrupt changes associated with inversions. Thus it occurs in conjunction with advective weather types, i.e. especially with northerly and westerly types. Type 7 can be related to convective situations, as well as type 8 . This is in agreement with the idea that only weak gradients allow the formation of stagnating air masses or large rotation angles.

These results, however, should be taken as tendencies rather than hard facts, since the scatter within the distribution cannot be neglected. A $\chi^{2}$ test revealed that the observed and the estimated distributions are correlated, but Pearson's contingency coefficient was only 0.46 . The simple classification scheme has its limits.

\section{Conclusions}

We have tried to extract information concerning the coupling/decoupling of the near-mountain wind field from routinely gathered radiosounding data. The emphasis has been put upon the vertical structure of the lower troposphere from ground to $6200 \mathrm{~m}$ asl with data points at height intervals of $150 \mathrm{~m}$. The dataset consisted of 3652 soundings or five years $(1981-85)$.

It could be shown that in the mean (i.e. with all cases) there is no distinct level where abrupt changes of any parameters could be observed. Rather, a smooth variation of the characteristics throughout the lower troposphere indicates the continuous decrease of the influence of the Jura mountains and the Alps on the atmosphere. Depending on atmospheric stability, the channelling of the airflow can be felt up to about, but not higher than, the $500 \mathrm{hPa}$ level. Countercurrents are a relatively frequent phenomenon, but are restricted to heights below the crest of the Jura mountains. Some sort of "splitting point" can be localized in a direction of $330^{\circ}$. The lowest few levels are dominated by the wind system of the Broye valley. These results are in good agreement with earlier studies, but are based on a longer time series with a much finer vertical resolution of datapoints.

The climatological treatment of the data conceals, however, that in individual cases the structure of the atmosphere allows one to easily identify levels of strong decoupling marked by jumps in the mean characteristics of the respective layers. 
Some exchange mechanism (e.g., vertical flux of momentum and energy) has to be regarded as relevant for the coupling of different layers, but a satisfactory discussion of this problem cannot be given since the restrictions due to missing 3dimensionality of the dataset are quite grave. Consequently, many of the observed features cannot be explained without doubt. The characteristics of the always turbulent boundary layer cannot be resolved in a satisfactory manner by routine soundings, which leaves an additional gap in our knowledge concerning the shape of wind profiles. Thus, many of our questions on the relation between the wind fields at the surface and aloft still lack their answers.

In spite of these adversities we found that roughly two thirds of the profiles show decoupling. We conclude that a simple extrapolation of the $500 \mathrm{hPa}$ wind field to the surface is unreliable in general. It is suggested that this complexity of the wind structure is the signal of the specific topographic situation of Payerne. It would be very interesting to perform a similar study for a station in plain topography, e.g., for Trappes near Paris (France).

Besides the near-neighbour interaction, the far field influence on a local profile has been studied. The simple classification scheme developed exhibited in its tendencies a certain correspondence with the weather types of Schüepp (1979), however the scatter of the data was considerable. A disadvantage of this profile type classification is its visual (or manual) type-assignment procedure. The subjectivity of this procedure could not totally be removed by objective criteria, and here some improvements should be made in the future.

On the other hand, the dataset reveals some features of atmospheric flow near mountain ranges in a resolution not common to similar studies. The influence of the topography yields wind profiles of great complexity, and until today no climatology of such profiles existed. This study presents a first, though preliminary, approach to this subject.

\section{Acknowledgements}

The author is much indebted to $\mathrm{H}$. Wanner and H. C. Davies for many discussions and to the Swiss Meteorological Institute, especially to J. Rieker and his crew in Payerne, for providing the data. This study was originally performed at the Institute of Geography of the University of Berne. It has been sponsored by the Swiss National Science Foundation as a contribution to the national research programme NFP14.

\section{References}

Bahrenberg, G., Giese, E., Nipper, J., 1985: Statistische Methoden in der Geographie. Vol. 1: Univariate und bivariate Statistik. Stuttgart: B. G. Teubner, 227 p.

Binder, P., Davies, H. C., Horn, J., 1989: Free atmosphere kinematics above the northern Alpine foreland during the ALPEX-SOP. Beitr. Phys. Atmos., 62, 30-45.

Cehak, K., Pichler, H., 1968: Beschreibung des Stromfeldes im Alpenbereich mittels Windmatrizen. Arch. Met. Geoph. Biokl., Ser. A, 17, 61-77.

Essenwanger, O. M., 1974: The structure of the wind profile from surface to $25 \mathrm{~km}$ in various climatic zones. Bonner Meteor. Abh., 17, 523-539.

Furger, M., 1990: Die Radiosondierungen von Payerne. Dynamisch-klimatologische Untersuchungen zur Vertikalstruktur des Windfeldes. Diss. phil. nat. Univ. Bern, Verlag Lenticularis, Opfikon, $191 \mathrm{p}$.

Furger, M., Wanner, H., Engel, J., Troxler, F. X., Valsangiacomo, A., 1989: Zur Durchlüftung der Täler und Vorlandsenken der Schweiz. Resultate des Nationalen Forschungsprogrammes 14. Geographica Bernensia, P 20, 162 p.

Gross, G., Wippermann, F., 1987: Channeling and countercurrent in the Upper Rhine Valley: Numerical simulations. J. Climate. Appl. Meteor., 26, 1293-1304.

Hoinka, K. P., 1985: Observation of the airflow over the Alps during a foehn event. Quart. J. Roy. Meteor. Soc., 111,199-224.

McKendry, I. G., Sturman, A. P., Owens, I. F., 1986: A study of interacting multi-scale wind systems, Canterbury plains, New Zealand. Meteorol. Atmos. Phys., 35, 242-252.

Reuter, H., Pichler, H., Cehak, K., 1966: Einfluss des Alpenmassivs auf die Häufigkeitsverteilung der Windrichtung in verschiedenen Niveaus. Forschungsbericht " $\mathrm{Al}$ penwetter", 7/66, Wien, $50 \mathrm{p}$.

Richner, H., Phillips, P. D., 1984: The radiosonde intercomparison SONDEX, spring 1981, Payerne. Pure Appl. Geophys., 120, 851- 1189.

Schüepp, M., 1979: Witterungsklimatologie. Beiheft Ann. Schweiz. Meteor. Anstalt, 93 p.

Seibert, P., 1985: Fallstudien und statistische Untersuchungen zum Südföhn im Raum Tirol. Diss. phil. nat. Univ. Innsbruck, 2 Vol., 369 p.

Shutts, G. J., Kitchen, M., Hoare, P. H., 1988: A large amplitude gravity wave in the lower stratosphere detected by radiosonde Quart. J. Roy. Meteor. Soc., 114, 579-594.

Steinacker, R., Klötzer, W., Lanzinger, A., 1987: The quality of ALPEX level-II b SYNOP and RAWIN data. Part III: RAWIN randomly distributed errors. Inst. Meteor. Geoph. Innsbruck, 41 p.

Steinacker, R., Klötzer, W., Lanzinger, A., 1988: The quality of ALPEX level-II b SYNOP and RAWIN data. Part IV: 
RAWIN systematic errors. Inst. Meteor. Geoph. Innsbruck, $41 \mathrm{p}$.

Wanner, H., Furger, M., 1990: The Bise - climatology of a regional wind north of the Alps. Meteorol. Atmos. Phys., 43, 105-116.

Wippermann, F., 1984: Air flow over and in broad valleys:
Channeling and counter-current. Beitr. Phys. Atmos., 57, $92-105$.

Author's address: Dr. Markus Furger, Paul Scherrer Institute, LUS/Environmental Research and Systems Analysis, CH-5232 Villigen PSI, Switzerland. 